Journal of

Cardiology and Vascular Medicine

\title{
Angiographic Predictors for the Development of Right Ventricular Cardiogenic Shock in Patients Presenting with Inferior Wall ST-Elevation MI
}

\author{
Matan Mor ${ }^{3,2}$, Oren Yagel ${ }^{4,1}$, Moshe Rav-Acha ${ }^{5,1}$, David Leibowitz ${ }^{4,1}$, Ronny Alcalai ${ }^{4,1, *}$ \\ ${ }^{1}$ Hadassah Faculty of Medicine, Hebrew University, Jerusalem, Israel \\ ${ }^{2}$ Sackler Faculty of Medicine, Tel Aviv University, Tel Aviv, Israel \\ ${ }^{3}$ Yitzhak Shamir Medical Center (formerly Assaf Harofeh Medical Center), Zerifin, Israel \\ ${ }^{4}$ Cardiac care unit, Mt. Scopus, Hadassah Hebrew University Medical Center, Jerusalem \\ ${ }^{5}$ Department of Cardiology, ShaareZedek Medical Center, Jerusalem, Israel
}

*Corresponding author: Ronny Alcalai, MD, Cardiac Care Unit, Mt. Scopus, Hadassah Hebrew University Medical Center, PO Box 12000, Jerusalem, Israel 91120, Tel: +972-25844530, Fax: +972-25845459, Email: ronny@hadassah.org.il

Received Date: November 05, 2019 Accepted Date: November 30, 2019 Published Date: December 03, 2019

Citation: Matan Mor (2019) Angiographic Predictors for the Development of Right Ventricular Cardiogenic Shock in Patients Presenting with Inferior Wall ST-Elevation MI. J Cardio Vasc Med 5: 1-10.

\begin{abstract}
Background: Acute right ventricular infarction (RVI) is associated with hemodynamic and electrical complications and worse prognosis. The ability to predict which patients with inferior wall ST-elevation MI will develop right ventricular cardiogenic shock is limited.

Methods: Consecutive patients admitted with STEMI secondary to occlusion of the right coronary artery were retrospectively analyzed. The association between demographic, angiographic and clinical characteristics and the development of cardiogenic shock due to right ventricular failure was evaluated. The accuracy of angiographic factors for the prediction of cardiogenic shock was assessed.

Results: Out of 152 patients, 14 (9.21\%) developed cardiogenic shock because of right ventricular failure. Three of them (21.42\%) died during hospitalization. There were no deaths in patients without cardiogenic shock. In the cardiogenic shock group, $92.9 \%$ of patients had aculprit lesion in the proximal RCA and $78.6 \%$ of patients had multi-vessel coronary disease, compared to $42.8 \%$ and $39.1 \%$ in patients without shock. Proximal RCA occlusion, multivessel coronary disease, and failure of reperfusion were independent predictors for cardiogenic shock (ORs 15.7, 5.3 and 4.7 respectively).

Conclusion: A culprit lesion in the proximal right coronary artery, the presence of multi-vessel disease and failure of reperfusion are strong predictors for the development of cardiogenic shock in patients presenting with inferior wall STEMI. Identification of these simple variables routinely available in the diagnostic angiogram performed upon admission may warrant careful and prolonged monitoring in the ICU, in order to identify early signs of cardiogenic shock.
\end{abstract}

Keywords: multi-vessel disease; cardiogenic shock; angiography; right coronary artery; collateral circulation

(C)2019 The Authors. Published by the JScholar under the terms of the Creative Commons Attribution License http://creativecommons.org/licenses/ by/3.0/, which permits unrestricted use, provided the original author and source are credited. 


\section{Introduction}

Right ventricular infarction (RVI) accompanies 30-50\% of the cases of acute inferior wall ST-segment elevation myocardial infarction (STEMI), but can also occasionally occur in the setting of anterior wall infarction [1-6]. The clinical presentation of RVI varies from no hemodynamic compromise to cardiogenic shock and multi-organ failure $[1,3,7,8$, . Right ventricular involvement in inferior-wall infarction is associated with higher rates of major complications and increased in-hospital-mortality [2,3,7,9-14]. Although the short-term prognosis for RVI is poor, patients who survive the hospitalization show better long-term prognosis compared to patients with shock due to LV failure [15].

Right, ventricular ischemia may lead to systolic and diastolic dysfunction, resulting in decreased LV preload causing reduced cardiac output and systemic hypotension. Patients with severe right ventricular infarction develop a distinct hemodynamic syndrome characterized by severe right heart failure, clear lungs, and low cardiac output despite intact left ventricle systolic function [3,16-19]. Adequate filling (preload) of the impaired RV is crucial to maintain sufficient cardiac output [20]. Clinically significant RVI occurs less often than would be expected based on the frequency of RCA related STEMI [16] and in many cases, it overlooked until significant hemodynamic deterioration is present. This may be explained by lower oxygen requirements of the RV due to its smaller muscle mass and workload [17], ability to down regulate its metabolic demand during coronary hypoperfusion [18] and more extensive collateralization of the RV [19-21]. The hemodynamic consequences of right ventricular infarction may appear unexpectedly, and it is crucial to have an early, simple and sensitive diagnostic tool to diagnose RVI before complications ensue in order to provide life-saving treatments [21].

Many studies have examined different modalities for the early diagnosis of RV infarction with inconsistent results. Originally, RVI was defined by invasive hemodynamic criteria, currently, however, most coronary units identify RV infarction using non-invasive techniques [22]. Both invasive and noninvasive methods have very poor capabilities for the prediction of consequent cardiogenic shock [3].

ST changes may be seen in aright pericardial lead ECG (V4R), nevertheless, the sensitivity of ECG as an a predictor for complicated RVI is limited. Some studies indicate the ST elevation in V4R may be transient and can disappear within 2-10 hours of the onset of chest pain $[21,23]$. In addition, the exten- sion of the infarction to the LV lateral wall could cancel out the ST elevation in V4R because of an opposing electrical vector [21]. Echocardiography [24-26] is also a limited tool to predict complications of RVI as imaging of the RV has technical challenges due to the chamber's complex shape. Echocardiographic evidence of right ventricular dysfunction does not correlate well with abnormal hemodynamics [19].

Global RV performance is predominantly determined by the RV free wall, which is perfused primarily by the $\mathrm{RV}$ branches of the right coronary artery. In addition, branches from the left coronary system anastomose with the RV branches through $1000 \mu \mathrm{m}$ diameter arterioles [27]. Furthermore, there is a comparatively greater likelihood of acute collateral development to the RCA compare to the left coronary system, attributable in part to lower coronary resistance that favors left to right trans-coronary pressure gradient [28]. For these reasons, both the location of the occlusion within the RCA, as well as the presence of left coronary disease, would seem to be important in predicting the extent of RV dysfunction and the subsequent hemodynamic consequences.

Currently, most patients with acute STEMI are treated with primary PCI and undergo coronary angiography upon presentation. The aim of this study is to examine the predictive value of angiographic variables for the development of cardiogenic shock due to RVI.

\section{Materials and Methods}

\section{Design}

Consecutive patients with the diagnosis of acute ST-elevation myocardial infarction hospitalized between 2006-2009 in Hadassah Medical Center, who underwent coronary angiography within 48 hours from symptom onset, and in whom the culprit lesion was found in the right coronary artery (RCA) were included in this retrospective observational study. Patients who underwent $\mathrm{CABG}$ prior to the admission were excluded. Informed consent was exempted by the Institutional review board due to the retrospective design.

\section{Data collection and definitions}

Demographic, clinical, laboratory, angiographic and echocardiographic data were collected from the computerized hospital database. The study population was divided into two subgroups: patients who developed cardiogenic shock due to RV failure during hospitalization (RV shock group), and patients who did not develop shock (control group). RV shock was de- 
fined as a combination of hypotension (systolic blood pressure below $90 \mathrm{mmHg}$ and/or diastolic below 60mmHg), clinical evidence of tissue perfusion injury (cold extremities, cyanosis, oliguria or altered mental status), jugular venous distention and clear lungs.

Angiographic definitions: the RCA lesion was defined as proximal if the culprit lesion was proximal to the first major RV branch. The presence of multi-vessel disease (MVD) was defined as stenosis of more than $70 \%$ in at least one major coronary vessel in the left system (left main, left anterior descending, or left circumflex) in addition to the RCA. Thrombolysis-In-Myocardial-Infarction flow (TIMI) score in the RCA was assessed before and after PCI. The definition was determined after each procedure was reviewed by an expert interventional cardiologist.

The function of both ventricles was evaluated during the first 24 hours of hospitalization using trans-thoracic echocardiography.

The primary outcome was the development of RV shock as defined above. Secondary outcomes included in-hospital death and the presence of significant arrhythmias (AV block, atrial fibrillation, ventricular tachycardia or ventricular fibrillation).

\section{Statistical analysis}

Continuous variables were compared using the non-parametric Mann-Whitney test. The use of a non-parametric test was due to the small sample size and the abnormal distribution of the variables. Categorical variables were assessed with chi-square or Fisher's exact tests when appropriate. Continuous variables were presented as mean $+\mathrm{SD}$ whereas categorical variables as count and percentages. Logistic regression analysis, by stepwise likelihood ratio method, was used to assess the independent predictors for RV shock. Variables that were found to be associated with the dependent variable (i.e., development of RV shock), were included in the multivariant logistic regression. Odds ratios were calculated with corresponding 95 percent confidence intervals. All p-values were determined with two-tailed tests. A p-value of less than 0.05 was considered statistically significant.

\section{Results}

One hundred fifty-two patients were diagnosed with ST-elevation myocardial infarction due to RCA occlusion and were included in the analysis. Fourteen (9.21\%) developed RV shock. There were no significant differences between the study subgroups in the baseline demographics, although a trend of a higher rate of previous coronary artery disease in the shock group was noted (Table 1).

\section{Clinical and laboratory data}

The maximal CPK and creatinine during hospitalization were higher in the RV shock group, and there was a trend towards higher troponin T levels. A higher incidence of arrhythmias were noted in the RV shock group, most significantly ventricular arrhythmias. Door-to-balloon time was available for only one-third of the patients and was longer in the shock group (Table 2). In-hospital mortality was significantly greater in the RV shock group $(21.4 \%$ vs $0 \%, \mathrm{p}<0.001)$.

\section{Angiographic and Echocardiographic data}

The culprit lesion was found in the proximal RCA in 92.9\% of the patients in the RV shock group as compared to $42.8 \%$ of patients in the control group $(\mathrm{p}<0.001)$. In addition, the multi-vessel coronary disease was significantly more frequent in the shock group (table 3 ). There was no difference in the TIMI flow score in the RCA in the initial angiography before PCI, but it was significantly worse after PCI in the RV shock group. Both $\mathrm{RV}$ and LV function as assessed by echocardiography were significantly poorer in the shock group (Table 3 ).

\section{Multivariate analysis}

In stepwise logistic regression, the angiographic variables MVD, proximal-RCA-lesion, and TIMI-flow-post-PCI were found to be independent predictors for RV shock (Table 4). The presence of both MVD and proximal-RCA-lesion was found to be the most significant angiographic predictor for the development of RV shock (Table 4). Other factors that are available upon admissions such as background medical history, risk factors, vital signs or TIMI flow before PCI were not found to be significant independent predictors for RV shock. We did not include in the model variables that not available on admission (such as biomarker levels and renal failure) as the purpose of the study was concentrate on factors available shortly after the presentation.

\section{Accuracy analysis}

We assessed the accuracy of these angiographic variables for the prediction of the development of RV shock. The assessment was done for each variable alone and for the combinations (Table 5). The combination of two variables (proximal-RCA-lesion and MVD)was a powerful predictor for the 
development of shock in STEMI patients, with $71 \%$ sensitivity, $84.1 \%$ specificity, the positive predictive value of $31.3 \%$, negative predictive value of $96.7 \%$, and overall accuracy of $82.9 \%$ (table $5)$. The combination of all three angiographic variables had lower sensitivity (42.9\%) but overall better diagnostic accuracy (89.6\%, table 5).

\begin{tabular}{|l|ll|ll|}
\hline Characteristic & Total(N=152) & Control(N=138) & RV shock(N=14) & P-Value \\
\hline Gender (Male), n(\%) & $124(81.6 \%)$ & $111(80.4 \%)$ & $19(92.9 \%)$ & $\mathbf{0 . 4 6 8}$ \\
Age (years) & $59.3 \pm 11.3$ & $58.9 \pm 11.2$ & $63.0 \pm 12.2$ & 0.25 \\
\hline Hypertension, $\mathrm{n}(\%)$ & $65(42.8 \%)$ & $60(43.5 \%)$ & $5(37.5 \%)$ & $\mathbf{0 . 5 7 6}$ \\
Diabetes Mellitus, $\mathrm{n}(\%)$ & $40(26.3 \%)$ & $35(25.4 \%)$ & $5(37.5 \%)$ & $\mathbf{0 . 5 2 4}$ \\
\hline Smoking, $\mathrm{n}(\%)$ & $101(66.4 \%)$ & $91(65.9 \%)$ & $10(71.4 \%)$ & 0.774 \\
Prior CAD, $\mathrm{n}(\%)$ & $55(36.2 \%)$ & $47(34.1 \%)$ & $8(57.1 \%)$ & 0.087 \\
\hline
\end{tabular}

Table 1 - Baseline demographics CAD - Coronary artery disease

\begin{tabular}{|c|c|c|c|c|}
\hline Characteristic & Total $(\mathrm{N}=152)$ & $\begin{array}{l}\text { Control } \\
(\mathrm{N}=138)\end{array}$ & $\begin{array}{c}\text { RV shock } \\
(\mathrm{N}=14)\end{array}$ & P-Value \\
\hline \multicolumn{5}{|l|}{ Arrhythmias, $\mathrm{n}(\%)$} \\
\hline Non & $111(73.0 \%)$ & $108(78.3 \%$ & $3(21.4 \%)$ & \\
\hline AVB / Bradycardia & $19(12.5 \%)$ & $16(11.6 \%)$ & $3(21.4 \%)$ & $\mathrm{p}<0.001$ \\
\hline $\mathrm{AF}$ & $6(3.9 \%)$ & $4(2.9 \%)$ & $2(14.3 \%)$ & \\
\hline $\mathrm{VT} / \mathrm{VF}$ & $16(10.5 \%)$ & $10(7.2 \%)$ & $6(42.9 \%)$ & \\
\hline Pulse (BPM) & $71 \pm 18$ & $72 \pm 17$ & $66 \pm 29$ & 0.254 \\
\hline \multicolumn{5}{|l|}{ Blood pressure(mmHg) } \\
\hline Systolic & $125 \pm 27$ & $128 \pm 26$ & $91 \pm 17$ & $\mathrm{p}<\mathbf{0 . 0 0 1}$ \\
\hline Diastolic & $74 \pm 15$ & $75 \pm 14$ & $58 \pm 15$ & $\mathrm{p}<\mathbf{0 . 0 0 1}$ \\
\hline $\operatorname{Max} \mathrm{CPK}(\mu \mathrm{g} / \mathrm{L})$ & $1481 \pm 1623$ & $1282 \pm 1212$ & $3424 \pm 3248$ & 0.007 \\
\hline Max Troponin T (ng/mL) & $3.51 \pm 4.78$ & $3.00 \pm 3.63$ & $8.46 \pm 9.82$ & $\underline{0.055}$ \\
\hline Max Creatinine $(\mu \mathrm{mol} / \mathrm{L})$ & $105 \pm 50$ & $97 \pm 27$ & $189 \pm 116$ & $\mathrm{p}<\mathbf{0 . 0 0 1}$ \\
\hline $\begin{array}{l}\text { Door to Balloon time(min- } \\
\text { utes) }\end{array}$ & $71 \pm 51$ & $66 \pm 48$ & $115 \pm 60$ & $\underline{0.052}$ \\
\hline
\end{tabular}

Table 2 - Clinical characteristics

AVB -AV block, AF - Atrial fibrillation, VT - Ventricular tachycardia, VF - Ventricular fibrillation, BPM- beats per minute 


\begin{tabular}{|c|c|c|c|c|}
\hline Characteristic & Total $(\mathrm{N}=152)$ & Control (N=138) & RV shock $(\mathrm{N}=14)$ & p-Value \\
\hline \multicolumn{5}{|l|}{ RCA location } \\
\hline \multirow[t]{2}{*}{ Proximal } & $72(47.4 \%)$ & $59(42.8 \%)$ & $13(92.9 \%)$ & \multirow[t]{2}{*}{$\mathrm{p}<0.001$} \\
\hline & $80(52.6 \%)$ & $79(57.2 \%)$ & $1(7.1 \%)$ & \\
\hline MVD & $65(42.8 \%)$ & $54(39.1 \%)$ & $11(78.6 \%)$ & 0.004 \\
\hline \multicolumn{5}{|l|}{ TIMI flow before PCI } \\
\hline \multirow[t]{2}{*}{$0-2$} & $71(49.1 \%)$ & $100(76.4 \%)$ & $13(92.8 \%)$ & \multirow[t]{2}{*}{0.091} \\
\hline & $32(22.1 \%)$ & $31(23.7 \%)$ & $1(7.1 \%)$ & \\
\hline \multicolumn{5}{|l|}{ TIMI flow post PCI } \\
\hline $0-2$ & $32(22.2 \%)$ & $3(17.7 \%)$ & $9(64.3 \%)$ & \multirow[t]{2}{*}{$\mathrm{p}<0.001$} \\
\hline 3 & $112(77.8 \%)$ & $107(82.3 \%)$ & $5(35.7 \%)$ & \\
\hline \multicolumn{5}{|l|}{ LV function } \\
\hline \multirow{3}{*}{$\begin{array}{l}\text { Normal } \\
\text { Mild to moderate dys- } \\
\text { function }\end{array}$} & $51(41.5 \%)$ & $47(42.3 \%)$ & $4(33.3 \%)$ & \multirow{3}{*}{0.022} \\
\hline & $61(49.6 \%)$ & $57(51.4 \%)$ & $4(33.3 \%)$ & \\
\hline & $11(8.9 \%)$ & $7(6.3 \%)$ & $4(33.3 \%)$ & \\
\hline \multicolumn{5}{|l|}{ RV function } \\
\hline Normal & $93(75.0 \%)$ & $91(82.0 \%)$ & $2(15.4 \%)$ & \multirow{2}{*}{$\mathrm{p}<0.001$} \\
\hline Any dysfunction & $31(25.0 \%)$ & $20(18.0 \%)$ & $11(84.6 \%)$ & \\
\hline
\end{tabular}

Table 3 - Angiographic and Echocardiographic Data

RCA - Right coronary artery, MVD - Multi-vessel disease, PCI - Percutaneous intervention, LV - Left ventricle, RV - Right ven-

\begin{tabular}{|l|cc|c|}
\hline Variable & Adjusted OR & 95\%C.I. for OR & P-Value \\
\hline MVD & 5.3 & $1.3-22.3$ & $\mathbf{0 . 0 2 3}$ \\
Proximal RCA location & 15.7 & $1.9-130.1$ & $\mathbf{0 . 0 1 1}$ \\
\hline TIMI flow post PCI & 4.9 & $1.3-18.3$ & $\mathbf{0 . 0 1 7}$ \\
MVD + Proximal RCA & 10.8 & $2.9-40.5$ & $<\mathbf{0 . 0 0 1}$ \\
location & & & \\
\hline
\end{tabular}

Table 4 - Logistic Regression of angiographic variables for the prediction of RV shock

RCA - Right coronary artery, MVD - Multi-vessel disease, PCI - Percutaneous intervention 


\begin{tabular}{|c|c|c|c|c|c|c|}
\hline Variable & Sensitivity & Specificity & PPV & NPV & $\begin{array}{l}\text { Overall } \\
\text { accuracy }\end{array}$ & P-Value \\
\hline MVD & $78.6 \%$ & $60.9 \%$ & $16.9 \%$ & $96.6 \%$ & $62.5 \%$ & 0.004 \\
\hline Prox RCA location & $92.9 \%$ & $57.2 \%$ & $18.1 \%$ & $98.8 \%$ & $60.5 \%$ & $<0.001$ \\
\hline Impaired TIMI flow post PCI & $64.3 \%$ & $84.0 \%$ & $30.0 \%$ & $95.7 \%$ & $82.1 \%$ & $<0.001$ \\
\hline MVD + Prox RCA location & $71.4 \%$ & $84.1 \%$ & $31.3 \%$ & $96.7 \%$ & $82.9 \%$ & $<0.001$ \\
\hline $\begin{array}{l}\text { Any two out of: MVD;Prox RCA } \\
\text { location; Impaired TIMI flow post } \\
\text { PCI }\end{array}$ & $92.9 \%$ & $79.0 \%$ & $31.0 \%$ & $99.1 \%$ & $80.3 \%$ & $<0.001$ \\
\hline $\begin{array}{l}\text { MVD + Prox RCA location + im- } \\
\text { pairedTIMI flow post PCI }\end{array}$ & $42.9 \%$ & $94.6 \%$ & $46.2 \%$ & $93.9 \%$ & $89.6 \%$ & $<0.001$ \\
\hline
\end{tabular}

Table 5 - Accuracy of angiographic data for development of RV shock

PPV - Positive predictive value; NPV - negative predictive value, Prox - Proximal, RCA - Right coronary artery, MVD Multi-vessel disease, PCI - Percutaneous intervention

\section{Discussion}

As of today, there is limited data regarding the early prediction of cardiogenic shock because of RV failure among patients with inferior wall STEMI. In our study, nearly $10 \%$ of patients admitted with STEMI due to occlusion of the RCA, developed RV cardiogenic shock. We found that easily assessed angiographic data was able to significantly predict the risk for this hemodynamic deterioration. The presence of multi-vessel coronary disease was found to increase the risk of RV shock 5.3-fold, proximal RCA lesion15.7-fold, and impaired TIMI flow post PCI 4.9-fold. The combination of all three angiographic variables created an even more accurate predictor (diagnostic accuracy of 89.6\%) for the development of RV shock.

The finding that more proximal lesions were predictive of hemodynamic deterioration is logical as the closer the lesion is to the origin of the RCA, the larger the amount of myocardium at risk $[28,5]$. Several previous studies demonstrated a worse prognosis for patients with proximal RCA lesions compared with distal occlusions. Bowers et al. [2] examined 125 patients with acute inferior MI who underwent emergency angiography. They found that all the patients who had RV infarction with evident echocardiographic RV dysfunction (42\%), had a culprit lesion in the proximal RCA compromising flow to nearly all the major RV branches. Goldstein et al. [29] found occlusion proximal to the ventricular branches in $70 \%$ of 216 cases of inferior infarctions and showed their tendency to develop hypotension, AVB, and bradycardia. In accordance with our findings, proximal occlusion of the RCA was found to be a sensitive predictor for RV shock, however as a single variable its specificity and positive predictive value are relatively low $(57.2 \%, 18.1 \%$ respectively), and therefore as in our study, other angiographic data should be take into consideration.

Another reason for the poor prognosis for patients with proximal RCA lesions, is the tendency of the infarction to involve the right atrium which is supplied by branches arising from the proximal right coronary artery [30]. Under conditions of perfusion injury to the right ventricle, compensatory augmentation of right atrial contraction enhances right ventricular filling and performance, whereas loss of this atrial function, as in cases of proximal RCA lesions, might lead to hemodynamic compromise [31]. A study in a dog model [32] demonstrated a marked deterioration in the RV end-diastolic size, systolic pressure, and contraction in cases of RCA ligation with isolated ligation of the right atrial branch.

Arrhythmias often complicate RVI and are much more common compared with inferior STEMI without RV involve- 
ment. SA block, advanced AVB, severe bradycardia as well as sustained ventricular tachycardia, all leading to higher mortality rates [33], were found more often in patients with RVI [9,1113,34]. Complete SA or AV blocks leading to bradycardia and loss of atrioventricular synchrony account in part for the ventricular dysfunction [35] and the development of hypotension and shock [36]. Proximal RCA occlusion deprives blood flow to both natural pacemakers, whereas distal occlusion spares the SA node and, in some cases, also the AV branches. Consequently, both bradycardia and hypotension were far more common in patients with proximal RCA occlusion, compared to more distal occlusions [28].

Whether multi-vessel coronary disease increases the risk for the development of RV cardiogenic shock is less clear. It seems probable that an extensive flow of blood passes from the left coronary artery into the right ventricle in times of need, such as proximal right coronary artery occlusions. Farrer-Brown [27] described vessels from the left coronary artery that supply the right ventricle via arteries in the anterior margin of the free wall, the apex and the interventricular septum in normal healthy adults and infants. Anastomoses between the LAD and the RCA, up to $1000 \mu \mathrm{m}$ in diameter, were found in the posterior papillary muscle and the moderator band. Another study [37] indicated that when a large coronary artery becomes blocked, immediate restoration of flow depends on the collateral vasculature. The small collateral vessels dilate immediately to offer an alternative blood supply to the under-perfused myocardium. Furthermore Yaylak et al. [38] demonstrated reduced mortality in patients with inferior wall STEMI and significant coronary collateral circulation. The significantly higher rates of RV shock in a patient with the multi-vessel coronary disease found in the present study may indicate that multi-vessel disease decreases the ability of the left coronary arteries to support the right myocardium in the case of acute RCA occlusion, because of lower flow reserve through the collateral arteries. Although a history of ischemic heart disease was not significantly associated with RV shock, probably due to lack of power, it was still higher in the patients who eventually developed RV shock.

Our results are consistent with the importance of early reperfusion for the recovery of the right ventricle, as demonstrated in earlier studies [39-40,15]. Sub-optimal TIMI-flow score post catheterization (0-2) was significantly higher in the RV shock group and was found to increase the risk for cardiogenic shock 4.9-fold. It appears that when early and successful coronary perfusion is achieved, the incidence of RV shock is rather low regardless of the coronary anatomy [41].
In summary, as the right ventricular muscle mass and workload are smaller, less blood flow is required for proper perfusion. Hence, even if the RCA is occluded, the right ventricular muscle might have adequate perfusion through collaterals from the left coronary system, and therefore clinically significant $\mathrm{RV}$ infarction is a relatively rare event. However, if the coronary atherosclerosis is diffuse, and the reserves of the left coronary system are low, occlusion of the RCA could cause a critical perfusion deficit, particularly if the culprit lesion is closer to the origin of the RCA. Our results indicate that the combination of proximal RCA occlusion, multi-vessel coronary disease, and late or inadequate reperfusion carries a very high risk of nearly $50 \%$ for the development of RV shock. Patients who demonstrate those angiographic characteristics may benefit from careful and prolonged monitoring in the ICCU after PCI.

\section{Study limitation}

First RV shock is uncommon, especially in the primary PCI and early reperfusion era, thus, the sample size is relatively small, particularly for the RV shock group. Nevertheless, since the RV shock group had unique characteristics, we were able to find significant predictors even in this relatively small group. Secondly, this is a retrospective study, which cannot prove causal relations between the studied variables and outcome. Another limitation is the subjective nature of the angiographic interpretation. To minimize this potential bias, we selected basic and simple parameters and each procedure was reassessed by an expert interventional cardiologist.

\section{Conclusion}

Right ventricular infarction complicated by cardiogenic shock is a challenging clinical condition with high rates of morbidity and mortality. We found that angiographic evidence of proximal RCA lesion combined with multivessel coronary disease are strong predictors for the development of RV shock during hospitalization, especially if the reperfusion was inadequate. These data, which are easily available early after admission can help in decisions, regard invasive monitoring, fluid management, inotropic support and other preventive actions to avoid hemodynamic deterioration. 


\section{References}

1] Isner J M, Roberts W C (1978) Right Ventricular Infarction Complicating Left Ventricular Infarction secondary to Coronary Heart Disease: Frequency, Location, Associated Findings and Significance From Analysis of 236 Necropsy Patients With Acute or Healed Myocardial Infarction. Am J Cardiol 42: 885-894.

2] Bowers TR, O'Neill WW, Pica M, Goldstein JA (2002) Patterns of Coronary Compromise Resulting in Acute Right Ventricular Ischemic Dysfunction. Circ 106: 1104-1109.

3] Shah PK, Maddahi J, Berman DS, Pichler M, Swan HJC (1985) Scintigraphically Detected Predominant Right Ventricular Dysfunction in Acute Myocardial Infarction: Clinical and Hemodynamic Correlates and Implications for Therapy and Prognosis. JAm Coll Cardiol 6: 1264-1272.

4] Cabin HS, Clubb KB, Wackers FJT, Zaret BL (1987) Right ventricular myocardial infarction with anterior wall left ventricular infarction: An autopsy study. Am Heart J 113: 16-23.

5] Andersen HR, Falk E, Nielsen D (1987) Right Ventricular Infarction: Frequency, Size and Topography in Coronary Heart Disease: A Prospective Study Comprising 107 Consecutive Autopsies From a Coronary Care Unit. J Am Coll Cardiol 10:1223-1232

6] Barsheshet A, Hod H, Oieru D, Goldenberg I, Sandach A, Beigel R, et al. (2011) Right Precordial Lead (V4R) ST-Segment Elevation is Associated With Worse Prognosis in Patients With Acute Anterior Myocardial Infarction. JAm Coll Cardiol 58: 548-549.

7] Ondrus T, Kanovsky J, Novotny T, Andrsova I, Spinar J, Kala P (2013) Right ventricular myocardial infarction: From pathophysiology to prognosis. Exp Clin Cardiol 18: 27-30.

8] Horan LG, Flowers NC (1999) Right Ventricular Infarction: Specific Requirements of Management. Am Fam Physician 60: $1727-1734$.

9] Zehender M, Kasper W, Kauder E, Schönthaler M, Geibel A, Olschewski M, et al. (1993) Right ventricular infarction as an independent predictor of prognosis after acute inferior myocardial infarction. N Engl J Med 328: 981-988.

10] Jacobs AK, Leopold JA, Bates E, Mendes LA, Sleeper LA, White H, et al. (2003) Cardiogenic Shock Caused by Right Ventricular Infarction: A Report From the SHOCK Registry. J
Am Coll Cardiol 41: 1273-1279.

11] A Barrillon, $M$ Chaignon, L Guize and A Gerbaux (1975) Premonitory sign of heart block in acute posterior myocardial infarction. Br Heart J 37: 2-8.

12] Mehta SR, Eikelboom JW, Natarajan MK, Diaz R, Yi C, Gibbons RJ, et al. (2001) Impact of Right Ventricular Involvement on Mortality and Morbidity in Patients With Inferior Myocardial Infarction. J Am Coll Cardiol 37: 37-43.

13] Berger PB, Ruocco NA Jr, Ryan TJ, Jacobs AK, Zaret BL, Wackers FJ, et al. (1993) Frequency and Significance of Right Ventricular Dysfunction During Inferior Wall Left Ventricular Myocardial Infarction Treated with Thrombolytic Therapy (Results from the Thrombolysis in Myocardial Infarction TIMI] II Trial). Am J Cardiol 71:1148-1152.

14] Bueno H, López-Palop R, Bermejo J, López-Sendón JL, Delcán JL (1997) In-Hospital Outcome of Elderly Patients With Acute Inferior Myocardial Infarction and Right Ventricular Involvement. Circulation 96: 436-441.

15] Brodie BR, Stuckey TD, Hansen C, Bradshaw BH, Downey WE, Pulsipher MW (2007) Comparison of Late Survival in Patients With Cardiogenic Shock Due to Right Ventricular Infarction Versus Left Ventricular Pump Failure Following Primary Percutaneous Coronary Intervention for ST-Elevation Acute Myocardial Infarction. Am J Cardiol 99 (4).

16] Lloyd EA, Gersh BJ, Kennelly BM (1981) Hemodynamic Spectrum of "Dominant" Right Ventricular Infarction in 19 Patients. Am J Cardiol 48: 1016-1022.

17] Lorell B, Leinbach RC, Pohost GM, Gold HK, Dinsmore RE, Hutter Jr AM, et al. (1979) Right ventricular infarction: clinical diagnosis and differentiation from cardiac tamponade and pericardial constriction. Am J Cardiol 43: 465-471.

18] Cohn JN, Guiha NH, Broder MI, Limas CJ (1974) Right ventricular infarction: clinical and hemodynamic features. Am J Cardiol 33: 209-214.

19] Dell' Italia LJ, Starling MR, Crawford $\mathrm{MH}$, Boros BL, Chaudhuri TK, et al. (1984) Right ventricular infarction: identification by hemodynamic measurements before and after volume loading and correlation with noninvasive techniques. J Am Coll Cardiol 4: 931-939.

20] Goldstein JA, Vlahakes GJ, Verrier ED, Schiller NB, Botvinick E, et al. (1983) Volume loading improves low cardiac 
output in experimental right ventricular infarction. J Am Coll Cardiol 2: 270-278.

21] Klein HO, Tordjman TH, Ninio RE, Sareli PI, et al. (1983) The early recognition of right ventricular infarction: diagnostic accuracy of the electrocardiographic V4R lead. Circulation 67: 558-565.

22] Inohara T, Kohsaka S, Fukuda K, Menon V (2013) The challenges in the management of right ventricular infarction. Eur Heart J Acute Cardiovasc Care 2: 226-234.

23] Braat SH, Brugada P, de Zwaan C, Coenegracht JM, Wellens HJ (1983) Value of electrocardiogram in diagnosing right ventricular involvement in patients with an acute inferior wall myocardial infarction. Heart 49: 368-372.

24] Kurtuluś O, Ićli A, Go H (2003) New parameters in identification of right ventricular myocardial infarction and proximal right coronary artery lesion. Chest 124: 219-226.

25] Rajesh GN, Raju D, Nandan D, Haridasan V, Vinayakumar D, Muneer K, et al. (2013) Echocardiographic assessment of right ventricular function in inferior wall myocardial infarction and angiographic correlation to proximal right coronary artery stenosis. Indian Heart J 65:522-528.

26] Javed S, Rajani AR, Govinda swamy P, Radaideh GA, Abubaraka HA, Qureshi TI, et al. (2017) Right ventricular involvement in patients with inferior myocardial infarction, correlation of electrocardiographic findings with echocardiography data. J Pak Med Assoc 67: 442-445.

27] Farrer-Brown G (1968) Vascular Pattern of Myocardium of Right Ventricle of human heart. Br Heart J. 30: 679-686.

28] Goldstein JA (2002) Pathophysiology and Management of Right Heart Ischemia. J Am Coll Cardiol 40: 841-53.

29] Goldstein JA, Lee DT, Pica MC, Dixon SR, O'Neill WW (2005) Patterns of coronary compromise leading to bradyarrhythmias and hypotension in inferior myocardial infarction. Coron Artery Dis 16: 265-274.

30] Blair E (1961) Anatomy of the ventricular coronary arteries in the dog. Circ Res 9: 333-341.

31] JA Goldstein, B Barzilai, TL Rosamond, PR Eisenberg and AS Jaffe (1990) "Determinants of Hemodynamic Compromise With Severe Right Ventricular Infarction," Circulation, vol. 82 , no. 2 .
32] Goldstein JA, Barzilai B, Rosamond TL, Eisenberg PR, Jaffe AS (1990) Determinants of hemodynamic compromise with severe right ventricular infarction. Circulation 82: 359-368.

33] Zaputović L, Matana A, Kučić J, Roje J, Marinovic Đ, Rupčić A (1990) Prognostic significance of complete atrioventricular block in patients with acute inferior myocardial infarction with and without right ventricular involvement. Am Heart J 119: 823-828.

34] Braat SH, de Zwaan C, Brugada P, Coenegracht JM, Wellens HJ (1984) Right ventricular involvement with acute inferior wall myocardial infarction identifies high risk of developing atrioventricular nodal conduction disturbances. Am Heart J 107: 1183-1187.

35] Pfisterer M, Emmenegger H, Soler M, Burkart F (1986) Prognostic significance of right ventricular ejection fraction for persistent complex ventricular arrhythmias and/or sudden cardiac death after first myocardial infarction: relation to infarct location, size and left ventricular function. Eur Heart J 7: 289298.

36] Love JC, Haffajee CI, Gore JM, Alpert JS (1984) Reversibility of hypotension and shock by atrial or atrioventricular sequential pacing in patients with right ventricular infarction. Am Heart J 108: 5-13.

37] Rees JR (1969) The myocardial collateral circulation. Br Heart J 31: 1 .

38] Yaylak B, Altintas B, Ede H, Baysal E, Akyuz S, Bilge O, et al. (2015) Impact of coronary collateral circulation on in-hospital death in patients with inferior ST elevation myocardial infarction. Cardiol Res Pract.

39] Laster SB, Ohnishi Y, Saffitz JE, Goldstein JA (1994) Effects of reperfusion on ischemic right ventricular dysfunction. Disparate mechanisms of benefit related to duration of ischemia. Circulation 90:1398-1409.

40] Bowers TR, O'Neill WW, Grines C, Pica MC, Safian RD, Goldstein JA (1998) Effect of reperfusion on biventricular function and survival after right ventricular infarction 338: 933-940.

41] Harjai KJ, Boura J, Grines L, Goldstein J, Stone GW, Brodie B, et al. (2002) C. Comparison of effectiveness of primary angioplasty for proximal versus distal right coronary artery culprit lesion during acute myocardial infarction. Am J Cardiol 90:1193-1197. 
Submit your manuscript to a JScholar journal and benefit from:

I Convenient online submission

ฯ Rigorous peer review

- Immediate publication on acceptance

I Open access: articles freely available online

9. High visibility within the field

- Better discount for your subsequent articles

Submit your manuscript at http://www.jscholaronline.org/submit-manuscript.php 